Quaestio facti. Revista Internacional sobre Razonamiento Probatorio Quaestio facti. International Journal on Evidential Legal Reasoning Vol. 1 | 2020 pp. 359-382 Madrid, 2020

DOI: $10.33115 /$ udg_bib/qf.i0.22381 Marcial Pons Ediciones Jurídicas y Sociales

(C) Jordi Ferrer Beltrán ISSN: 2604-6202

Recibido: 10/06/2019 | Aceptado: 13/10/2019

\title{
SOBRE EL DEBER DE MOTIVACIÓN DE LAS DECISIONES PROBATORIAS Y EL JUICIO POR JURADOS. LA SENTENCIA V.R.P., V.P.C. Y OTROS VS. NICARAGUA DE LA CORTEIDH
}

\author{
Jordi Ferrer Beltrán* \\ Profesor titular de Filosofía del Derecho de la Universidad de Girona \\ y director de la Cátedra de Cultura Jurídica \\ y del Máster en razonamiento probatorio de la misma universidad. \\ jordi.ferrerb@udg.edu
}

RESUMEN: El artículo analiza, a partir de la sentencia V.R.P., V.P.C. y otros vs. Nicaragua de la CorteIDH, tres cuestiones principales: 1) el deber de motivación de las resoluciones judiciales en materia de hechos y su alcance; 2) las concepciones persuasiva o subjetivista y racional sobre la prueba; y 3) la interrelación entre 1) y 2) y su implementación en el caso de los juicios penales por jurados. Se critica la tesis de la CorteIDH de que un sistema de juicio por jurado, con decisión inmotivada y por íntima convicción, no es contrario a las garantías previstas en el art. 8.1 de la Convención Americana sobre Derechos Humanos.

PALABRAS CLAVE: Proceso penal. Juicio por jurados. Motivación de las sentencias. Estándares de prueba. Íntima convicción.

* Para la redacción de este trabajo he contado con el apoyo del proyecto de investigación «Seguridad jurídica y razonamiento judicial» (DER2017-82661-P), concedido por el Ministerio de economía y competitividad español. Agradezco su atenta lectura y sus útiles comentarios a Edgar Aguilera, Michele Taruffo y Carmen Vázquez. 


\section{ON THE JUSTIFICATION DUTY OF THE FINDINGS OF FACT AND THE JURY TRIALS. THE RULING V.R.P, V.P.C. Y OTROS VS. NICARAGUA}

ABSTRACT: Based on the ruling by the Inter-American Court of Human Rights in V.R.P., V.P.C. $y$ otros vs. Nicaragua, this paper analyses three main issues: 1) the judges' duty to justify their fact finding and its scope; 2) the persuasive (or subjective) and the rational approaches to evidence and proof; and 3) the interrelation between 1) and 2) and their implementation in criminal jury trials. It criticises the Inter-American Court's thesis that trial by jury systems, with no justified fact finding and by intime conviction, are not contrary to the guarantees provided by Article 8 of the American Convention of Human Rights.

KEYWORDS: Criminal Trial. Jury Trial. Justification of the fact-findings. Standards of Proof. Intime Conviction.

SUMARIO: 1. El caso a examen en la sentencia V.R.P., V.P.C. y otros vs. Nicaragua de la CorteIDH.- 2. La regulación legal nicaragüense sobre las decisiones probatorias de los jurados en casos penales.-3. Las alegaciones de la Comisión y la representación de las víctimas sobre la decisión inmotivada del jurado. - 4. La Corte sobre la falta de motivación y decisión del jurado por íntima convicción.- 5. Algunos comentarios al razonamiento de la Corte sobre el juicio por jurados, la íntima convicción y la ausencia de motivación. 5. 1. La concepción de la prueba. 5. 2. La concepción de la motivación. 5.3. El contenido de la motivación. 5.4. Razonamiento probatorio y jurado.-6. Bibliografía.

1. EL CASO A EXAMEN EN LA SENTENCIA V.R.P., V.P.C. Y OTROS VS. NICARAGUA DE LA CORTEIDH

La sentencia de la CorteIDH (en adelante, simplemente, la Corte) de 8 de marzo de 2018, tiene su origen en la violación de una niña de ocho años (V.R.P.) supuestamente cometida por su padre. El acusado fue juzgado en Nicaragua por los hechos mediante un procedimiento por jurado, repleto de irregularidades, y absuelto de todas las imputaciones. A partir de ahí, la madre de la niña (V.P.C.) formuló en 2002 una petición ante la ComisiónIDH (en adelante, simplemente, la Comisión), alegando la responsabilidad internacional de Nicaragua por las irregularidades del proceso y por la impunidad que dejó sin protección los derechos de su hija, dañando a toda la familia. En 2009 la Comisión aprobó el informe de admisibilidad de la petición formulada por la madre y en 2016 el informe de fondo, en el que se concluyó que se violaron los derechos establecidos en los arts. 5, 8, 11, 19, 24 y 25 de la Convención Americana sobre Derechos Humanos y en el art. 7.b) de la Convención Interamericana para prevenir, sancionar y erradicar la violencia contra la mujer (Convención de Belém do Pará), así como se formularon una serie de recomendaciones a Nicaragua, que no fueron objeto de respuesta alguna por el estado. En agosto de 2016 la Comisión sometió el caso a la jurisdicción de la Corte, solicitando la condena de Nicaragua por las violaciones a la Convención Americana sobre Derechos Humanos y de la Convención de Belém do Pará, así como diversos actos de reparación hacia la 
víctima directa y sus familiares (madre y hermanos). La representación de las víctimas se mostró de acuerdo con las alegaciones de la Comisión y añadió en las suyas la violación de algunos otros derechos reconocidos en la Convención de Belém do Pará y en la Convención sobre los Derechos del Niño.

El proceso seguido contra H.R.A., padre de la niña, a quien ésta y su madre identificaron como el autor de la violación, estuvo plagado de irregularidades y de un tratamiento indudablemente revictimizador de la menor, tanto en su fase de instrucción como de juicio oral. Así, por ejemplo, 1) la jueza de distrito penal de Jinotega, a cargo del caso, ordenó que se constituyera una junta médica con un pediatra, un ginecólogo y un cirujano para examinar a la niña, a los que se añadieron en el momento del examen médico una psiquiatra, la propia jueza y la secretaria del despacho judicial. Es decir, se pretendió realizar una revisión médica (vaginal y anal) a la niña en presencia de 6 personas, con un trato brusco y hasta vejatorio hacia aquella por parte del médico forense, lo que ocasionó que otros galenos abandonaran la sala y que la niña se negara completamente a permitir el examen médico. Posteriormente, se tuvo que repetir la diligencia médica, realizándola bajo anestesia en el Instituto de Medicina Legal de la Corte Suprema de Justicia en Managua y con ella se pudo comprobar que la niña tenía diversas lesiones vaginales y anales, así como enfermedades de transmisión sexual. 2) Se ordenó una inspección ocular judicial y reconstrucción de los hechos, en la que se pidió a la niña (de nueve años en ese momento) que relatara de nuevo todo lo ocurrido con su padre, que se encontraba en las inmediaciones, «se le pidió que recorriera y reconociera los mismos lugares a los que había sido llevada por su progenitor para recrear nuevamente lo ocurrido, así como que vistiera las mismas prendas que llevaba puestas cuando sucedieron los hechos, e incluso se le solicitó que se pusiera en "la misma posición en que se encontraba en el momento en que despertó"”, tomándose fotografías del lugar y de la niña en las posiciones que la jueza le fue indicando (pár. 88 de la sentencia). 3) El padre fue sometido a dos exámenes médicos para determinar si era portador de las enfermedades venéreas transmitidas a la hija. El primero fue realizado por el mismo médico forense que realizó el examen inicial a la niña (y cuyo hermano declaró como testigo de la defensa en el juicio) y el segundo por un médico forense del Instituto de Medicina Legal. Este último determinó que en el momento del reconocimiento no se observaba ninguna patología compatible con enfermedades venéreas, y recomendó que se realizara un «estudio de laboratorio para determinar virus de papiloma venéreo en muestras de semen y frotis de la piel de órganos genitales, para descartar posible patología de ser un portador sano de virus de papiloma venéreo» (pár. 91), pero el estudio de laboratorio nunca fue ordenado ni se realizó. 3) Antes del inicio de la audiencia de juicio oral se tuvieron que designar los miembros del jurado hasta en tres ocasiones, por diversas suspensiones. 4) El abogado del acusado solicitó que pudieran participar en la defensa otros dos abogados, lo que fue autorizado; sin embargo, no se autorizó lo mismo para la representación de la víctima. 5) Uno de los abogados del acusado entregó, al finalizar la vista pública, una bolsa gris y dos hojas de papel rosado a la presidenta del jurado, que el imputado solicitó que se leyeran en sesión privada del jurado. Las dos hojas no fueron incorpo- 
radas al expediente ni puesto su contenido en conocimiento de la acusación ni de la representación legal de la víctima y se desconoce el contenido de la bolsa gris.

A partir de ahí, el devenir procesal se divide en dos procesos, un recurso de nulidad presentado por la representación de la víctima contra la sentencia absolutoria y un proceso por cohecho contra los miembros del jurado. Después de un gran retraso en la tramitación, derivado entre otras cosas de que diversos jueces se excusaron sucesivamente de asumir el caso, los miembros del jurado fueron absueltos y la absolución del padre de la niña V.R.P. confirmada por la Sala Penal del Tribunal de Apelaciones de la Circunscripción Norte de Matagalpa. Se señala también como nueva irregularidad que la fiscal no se personó en el proceso en segunda instancia. Fueron diversas las quejas ante la Fiscalía General de la República de la madre de V.R.P. durante todo el proceso por la negligencia y dejadez de funciones de la fiscal auxiliar departamental al cargo del caso.

Como puede observarse, el caso está tan plagado de irregularidades que no resulta sorprendente que la Corte concluyera su sentencia con la condena al Estado de Nicaragua y ordenara diversas medidas reparadoras a favor de V.R.P., su madre y sus hermanos.

Sin embargo, el interés que suscita mi análisis en este trabajo es la alegación por parte de las representantes de las víctimas y de la Comisión de que se habría violado el derecho al debido proceso reconocido en el art. 8.1 de la Convención Americana sobre Derechos Humanos ${ }^{1}$. Esa violación se concretaría en el hecho de que el veredicto del jurado fue inmotivado y, de acuerdo con la legislación nicaragüense del momento, regido por el criterio de la íntima convicción. Por ello, antes de proceder con el análisis, vale la pena hacer un somero repaso de la regulación legal nicaragüense sobre las decisiones sobre los hechos probados que deben adoptar los jurados.

\section{LA REGULACIÓN LEGAL NICARAGÜENSE SOBRE LAS DECISIONES PROBATORIAS DE LOS JURADOS EN CASOS PENALES}

La Constitución nicaragüense de 1987, en su artículo 166, prevé la "participación popular» en la administración de justicia a través de los juicios por jurados, en los siguientes términos:

1 Dicho numeral establece literalmente que: «Toda persona tiene derecho a ser oída, con las debidas garantías y dentro de un plazo razonable, por un juez o tribunal competente, independiente e imparcial, establecido con anterioridad por la ley, en la sustanciación de cualquier acusación penal formulada contra ella, o para la determinación de sus derechos y obligaciones de orden civil, laboral, fiscal o de cualquier otro carácter» (la cursiva es mía). Comentaré más adelante la particularidad de que, en este caso, las garantías violadas no son las del acusado sino las de la víctima. 
La administración de justicia se organizará y funcionará con participación popular, que será determinada por las leyes. Los miembros de los Tribunales de Justicia, sean abogados o no, tienen iguales facultades en el ejercicio de sus funciones jurisdiccionales.

Esa participación popular, en el caso del proceso penal, se desarrolló legislativamente en el Código de Instrucción Criminal (ley procesal vigente en el momento de los hechos) y, posteriormente, en el vigente Código Procesal Penal. Así, el artículo 22 del Código de Instrucción Criminal establecía que:

los delitos comunes que merezcan penas más que correccional deberán ser sometidos al conocimiento del Tribunal de Jurados, quien emitirá su veredicto de intima convicción, pronunciándose sobre la responsabilidad del procesado declarándolo inocente o culpable. Con este veredicto el Juez de Distrito dictará su sentencia absolviendo, o imponiendo la pena (cursiva ańadida). Esta regulación se mantiene en el vigente Código Procesal Penal.

Y los arts. 290, 305 y 307 del mismo Código de Instrucción criminal ofrecían mayores detalles, estableciendo que:

Artículo 290: «Una vez reunidos los jurados, el juez recibirá la promesa de todos ellos en la forma siguiente: "¿Prometéis delante de Dios y delante de los hombres, examinar con escrupulosa atención el proceso que se os va a someter, no traicionar ni los intereses del acusado ni los de la sociedad que le acusa: no dejaros llevar por el odio, por la antipatía, por la malevolencia, por el temor ni por el afecto: resolver siguiendo vuestra conciencia e intima convicción con la imparcialidad y firmeza que conviene a un hombre probo y libre?", Cada uno de los jurados, llamados individualmente por el juez, responderá "Lo prometo"” (cursiva añadida).

Artículo 305: «Al quedar solos los jurados, el presidente les hará la siguiente advertencia que debe estar escrita con gruesos caracteres y fijada en la pieza en que se reúna el jurado: La ley no pide a los jurados cuenta de los medios por los cuales han llegado a formar su convencimiento, ni les prescribe reglas de las cuales deban deducir especialmente la certeza de los hechos. Ella les prescribe solamente interrogarse a sí mismos, y buscar en la sinceridad de su conciencia qué impresión han hecho en su razón las pruebas producidas en contra y en defensa del acusado. La ley no les dice tendréis por verdad tal hecho afirmado por tal número de testigos, ella no les hace sino esta sola pregunta, que resume todos sus deberes: “'Tenéis una íntima convicción?””(cursiva añadida) Artículo 307.3: "Cuatro votos en un mismo sentido, constituyen veredicto. En su caso, el jurado disidente, si lo tuviere a bien, podrá razonar su voto en un escrito separado que se agregará a la causa».

Pues bien, como puede observarse, las características del proceso penal por jurados previsto en la legislación procesal penal nicaragüense, como por otro lado es muy común en otros países, prevé que la decisión sobre los hechos probados sea adoptada mediante el criterio de la íntima convicción o decisión en conciencia, sin motivación. De hecho, la única previsión legal de motivación está prevista no para el veredicto sino para que el miembro del jurado disidente (si lo hay) pueda justificar su discrepancia con la decisión mayoritaria. 


\section{LAS ALEGACIONES DE LA COMISIÓN Y LA REPRESENTACIÓN DE LAS VÍCTIMAS SOBRE LA DECISIÓN INMOTIVADA DEL JURADO}

Tanto la representación de las víctimas como la Comisión en su informe de fondo sobre el caso consideraron violado el derecho al debido proceso por la falta de motivación del veredicto de primera instancia. Así, la Comisión «recordó que el deber de motivación es un corolario de las garantías del debido proceso, no solo desde la legitimidad misma de la decisión y la defensa de la persona acusada, sino también desde la expectativa de acceso a la justicia que tienen las víctimas de violaciones a sus derechos. Asimismo, indicó que el deber de motivar las resoluciones es una garantía vinculada con la correcta administración de justicia, además demuestra a las partes que éstas han sido oídas y, en aquellos casos en que las decisiones son recurribles, les proporciona la posibilidad de criticar la resolución y lograr un nuevo examen de la cuestión ante las instancias superiores» (párr. 210).

Las representantes de las víctimas, por su parte, abundando en el criterio de la Comisión, manifestaron que el carácter inmotivado del veredicto absolutorio había impedido conocer las razones en que se basó, la manera en que se valoraron las pruebas (en escasos 15 minutos de deliberación), si se tomaron en consideración los alegatos de la representación de las víctimas o si fueron determinantes el contenido desconocido de la bolsa gris y las hojas rosadas que se entregaron al jurado por la defensa para su lectura privada, o la presión política, por la pertenencia del acusado al Frente Sandinista (párr. 213).

De esta manera, tanto la Comisión como las representantes de las víctimas hacen una clara apelación a las denominadas funciones endoprocesales y extraprocesales de la motivación ${ }^{2}$. Por un lado, en efecto, el deber de motivar las resoluciones judiciales cumple una función dentro del propio procedimiento, haciendo posible para las partes conocer el razonamiento que ha llevado a la decisión y, con ello, fundar un posible recurso. Pero a esta clásica función endoprocesal se añaden también otras, que Colomer hernández (2003: 128 ss.) clasifica en función de sus destinatarios: las partes, el juzgador que decide el caso y los órganos jurisdiccionales superiores que pudieran tener que revisar la decisión en sede de recurso. La más importante de las funciones endoprocesales, en mi opinión, es la que cumple la motivación como límite a lo decidible ${ }^{3}$. Así, entendida la motivación como justificación de la decisión (sobre lo que volveré más adelante), el deber de motivar se traduce en el deber de tomar decisiones justificadas (siendo así una garantía de la correcta administración de

\footnotetext{
2 No es objeto de este trabajo la presentación detallada de las funciones de la motivación, que han sido profusamente desarrolladas por la doctrina y también por la jurisprudencia. Una buena presentación de las dos funciones, con abundantes y relevantes referencias bibliográficas, puede verse en Castillo Alva, 2013: 161 ss.

3 En este sentido, véase IACOvello, I997: 8, y Gascón Abellán, i 999: 202. Taruffo (1975: 386) habla incluso de la motivación como "condición de "jurisdiccionalidad" de los mandatos del juez, en el sentido de que los mismos constituyen expresión de la jurisdicción cuando se encuentran motivados».
} 
justicia, en términos de la Comisión). La función extraprocesal de la motivación, en cambio, la vincula con el control social de las decisiones judiciales y, en esta medida, con su legitimidad y con un modelo de poder judicial propio de un estado democrático de derecho basado en la publicidad ${ }^{4}$. Todas esas funciones de la motivación la sitúan entre lo que FerRajoli (1998: 639) denomina "garantías de segundo orden», con el valor de una garantía de cierre de un sistema garantista. Y todas ellas fueron mencionadas de forma directa o indirecta por la Comisión y las representantes de las víctimas en sus alegaciones, como fundamento de la pretendida violación del derecho al debido proceso por la falta de motivación.

\section{LA CORTE SOBRE LA FALTA DE MOTIVACIÓN Y DECISIÓN DEL JURADO POR ÍNTIMA CONVICCIÓN}

La respuesta de la Corte a las mencionadas alegaciones de violación del debido proceso en el caso juzgado siguió un recorrido intrincado, a veces por vericuetos jurídicos y otras por caminos de la «realpolitik». Veamos sus argumentos:

«La Corte ha definido el debido proceso legal como un conjunto de requisitos que deben observarse en las instancias procesales a efectos de que las personas estén en condiciones de defender adecuadamente sus derechos ante cualquier tipo de acto del Estado que pueda afectarlos» (párr. 217).

«En el presente caso, quien se reputa presunta víctima de la violación de estas garantías no es el inculpado del delito, destinatario originario de toda arquitectura ilustrada que procuraba poner coto al avance del poder punitivo del Estado, sino la agraviada del delito y su madre. En esta medida, la Corte recuerda que las "debidas garantías" del artículo 8.1. de la Convención amparan el derecho a un debido proceso del imputado y, en casos como el presente, también salvaguardan los derechos de acceso a la justicia de la víctima de un delito o de sus familiares y a conocer la verdad de los familiares» (párr. 218 y nota 281).

«En principio, nada excluye que las garantías judiciales recogidas en la Convención Americana sean aplicables al sistema de juicio por jurados, pues sus redactores no tenían en mente un sistema procesal penal específico» (párr. 219)

En este punto, recuerda la Corte que 21 de los 35 Estados que conforman la OEA prevén el juicio por jurados (párr. 223), lo que acabará constituyéndose, en mi opinión, en el motivo principal por el que las alegaciones de inconvencionalidad no fueron atendidas: hubiese tenido implicaciones de grandísimo calado en el diseño procesal penal de muchos países, sin que en el caso concreto la Corte tuviera necesidad de afrontar ese desafío para dar protección a las víctimas.

Así que prima la libertad de los Estados para decidir sobre la arquitectura de su proceso penal y, en concreto, sobre la previsión del juicio por jurados, sin que ello implique

4 Véanse, por todos, Andrés IbáŃez, i 992: i 8 I, Igartua Salaverría, 2003: 24-7 y Aliste SanTos, 2018: 156 ss. 
que los sistemas de enjuiciamiento por jurados queden al arbitrio del diseńo estatal o que la legislación interna tenga preeminencia sobre los requerimientos convencionales, sino que el diseño de los ordenamientos procesales debe responder a los postulados de garantía que exige la Convención Americana. Es en esta medida que la Corte deberá ejercer su control de convencionalidad para examinar si los procedimientos, tal como fueron diseñados e implementados por el Estado, se ajustan a los parámetros dictados por el artículo 8 (párr. 225).

Pero hasta aquí permanece sin respuesta la pregunta acerca de si un sistema de enjuiciamiento penal por jurados, como el nicaragüense, que deciden sobre los hechos por íntima convicción y sin motivación es o no compatible con el debido proceso. Es en este punto donde la Corte parece dar una respuesta clara, recordando su propia doctrina al respecto:

«La Corte ha señalado que "el deber de motivación es una de las 'debidas garantías' incluidas en el artículo 8.1 para salvaguardar el derecho a un debido proceso" »[sentencia Apitz Barbera y otros vs Venezuela -párr. 78- y sentencia Trabajadores cesados de Petroperú y otros vs. Perú -párr. 168]. «La Corte ha precisado que la motivación "es la exteriorización de la justificación razonada que permite llegar a una conclusión” [sentencia Chaparro Álvarez y Lapo Î́niguez vs. Ecuador -párr. 107-] y conlleva una exposición racional de las razones que llevan al juzgador a adoptar una decisión. La relevancia de esta garantía se encuentra ligada a la correcta administración de justicia y a evitar que se emitan decisiones arbitrarias. Asimismo, la motivación otorga credibilidad de las decisiones jurídicas en el marco de una sociedad democrática y demuestra a las partes que éstas han sido oídas» (párr. 254, cursiva añadida).

«Ello, se encuentra ligado con otro de los aspectos que realzan el valor de la motivación como garantía, que es proporcionar la posibilidad, en aquellos casos en que las decisiones son recurribles, de criticar la resolución y lograr un nuevo examen de la cuestión ante las instancias superiores. De este modo, la Corte ya ha señalado que "la motivación de la decisión judicial es condición de posibilidad para garantizar el derecho de defensa” " [caso Zegarra Marín vs. Perú, párrs 147 y 155]” (párr. 255).

Pero después de asumir casi palabra por palabra los argumentos de la Comisión y de la representación de las víctimas, que llevarían a la inconvencionalidad del juicio por jurados nicaragüense (y de muchos otros países), la Corte da un giro de 180 grados y de forma totalmente sorpresiva afirma que:

la falta de exteriorización de la fundamentación del veredicto no vulnera en si misma la garantía de la motivación. En efecto, todo veredicto siempre tiene motivación, aunque como corresponde a la esencia del jurado, no se expresa. Pero el veredicto debe permitir que, a la luz de las pruebas y el debate en la audiencia, quien lo valora pueda reconstruir el curso lógico de la decisión de los jurados, quienes habrían incurrido en arbitrariedad en el supuesto en que esta reconstrucción no fuera viable conforme a pautas racionales (párr. 259, cursiva ańadida) 5 .

5 En este punto la Corte menciona la doctrina coincidente del Tribunal Europeo de Derechos Humanos, en particular el caso Saric vs. Dinamarca, núm. 31913/96. Decisión de admisibilidad de 2 de febrero de 1999, pp. 14-5. Ciertamente, el TEDH ha enfrentado el mismo problema planteado en la sentencia analizada de la Corte y su solución ha sido prácticamente calcada, considerando que un veredicto inmotivado por parte de un jurado no constituye, en sí mismo, una violación del derecho del acusado a un juicio justo (sentencia Bellerin Lagares vs. España, de 4 de noviembre de 2003, y sentencia Taxquet vs. Bélgica, de 16 de noviembre de 2010). Véase, al respecto, Ovejero Puente, 2019: 208210. 
Esto es, después de decir que «la motivación "es la exteriorización de la justificación razonada que permite llegar a una conclusión”" (párr. 254) la Corte nos dice que «la falta de exteriorización de la fundamentación del veredicto no vulnera en si misma la garantía de la motivación» (párr. 259), sin temer ni por un momento caer en contradicción.

Todo ello se vincula con la voluntad de no declarar como contrario a la Convención Americana sobre Derechos Humanos la regulación nicaragüense del jurado (y, por extensión, de todos los países que tengan regulaciones análogas),

toda vez que histórica y tradicionalmente el veredicto del jurado en un sentido clásico no exigía una motivación o exteriorización de la fundamentación, ya que la apreciación de la prueba se basaba en la íntima convicción de los juzgadores (párr. 158).

Es por ello que la Corte reprocha a la Comisión que no realizara un análisis de las particularidades del jurado respecto del deber de motivar las decisiones.

Más aún, «todo veredicto siempre tiene motivación, aunque como corresponde a la esencia del jurado, no se expresa. Pero el veredicto debe permitir que, a la luz de las pruebas y el debate en la audiencia, quien lo valora pueda reconstruir el curso lógico de la decisión de los jurados, quienes habrían incurrido en arbitrariedad en el supuesto en que esta reconstrucción no fuera viable conforme a pautas racionales» (pár. 259, cursiva añadida).

De este modo, se salvaguardaría la función endoprocesal de la motivación, siempre que se pueda reconstruir (imaginar) el razonamiento que pueda haber llevado a la decisión. Y la función extraprocesal de la motivación, que otorga legitimidad a la decisión mediante «el control ciudadano de los actos de gobierno, en este caso de la administración de justicia, y los expone a su escrutinio», quedaría también salvaguardada en el caso del jurado puesto que dicha «vertiente se entiende cubierta en razón de la participación directa de la ciudadanía» (párr. 257) ${ }^{6}$.

Finalmente, afirma también la Corte que

[1]a íntima convicción no es un criterio arbitrario. La libre valoración que hace el jurado no es sustancialmente diferente de la que puede hacer un juez técnico, sólo que no lo expresa (párr. $262)^{7}$

${ }^{6}$ No dedicaré mi atención a este punto, pero entiendo muy atinada la crítica de SAGüÉs (2018: 1-2) de que, por un lado, con la participación de algunos ciudadanos elegidos al azar no puede en ningún caso considerarse que estos representan al pueblo en una suerte de justicia democrática, y, por el otro, aun si así fuera, de ello no se inferiría que ese tipo de enjuiciamiento pueda quedar fuera del escrutinio social y la publicidad. En el mismo sentido se había expresado también ANDrÉs IBÁÑ̄EZ, 2004: 176.

7 No es claro, entonces, si en atención a esto último un sistema de enjuiciamiento penal por jueces profesionales basado en la íntima convicción y sin motivación se consideraría también acorde con la Convención Americana sobre Derechos Humanos, con la condición de que se pudiera reconstruir (imaginar) el razonamiento que llevó al juez a decidir a partir de las pruebas presentadas. Y si no se acepta esto, la Corte debería argumentar cuáles son las diferencias que sí lo hacen acorde en el caso del jurado. 


\section{ALGUNOS COMENTARIOS AL RAZONAMIENTO DE LA CORTE SOBRE EL JUICIO POR JURADOS, LA ÍNTIMA CONVICCIÓN Y LA AUSENCIA DE MOTIVACIÓN}

En lo que sigue, presentaré cuatro comentarios sobre la relación entre prueba y motivación, así como sobre la vinculación entre estas dos y el jurado como instrumento de enjuiciamiento sobre los hechos.

Antes de dar paso a esos comentarios, sin embargo, vale hacer mención a una particularidad del caso en análisis: creo que puede decirse sin mayor necesidad de acreditación que el discurso de las garantías procesales (tanto a nivel doctrinal como en la legislación y los tratados internacionales), especialmente para el proceso penal, se ha construido pensando en el imputado como sujeto de las mismas. Basta ver aquí lo que se establece en la propia Convención Americana sobre Derechos Humanos ${ }^{8}$. Sin embargo, este mismo caso demuestra la insuficiencia de esa perspectiva y la necesidad de repensar las garantías procesales de un modo más equilibrado entre las partes del proceso. Ello no supone que deban disminuirse las garantías para el imputado, sino que se advierta que los suyos no son los únicos intereses que merecen protección?. En todo caso, este es un argumento demasiado complejo para ser abordado también en este trabajo.

\section{1. La concepción de la prueba}

Como se ha visto hasta aquí, la Corte valida la íntima convicción como criterio para la toma de decisiones sobre la prueba. Es claro que ello no supone que lo considere el único compatible con los derechos y garantías reconocidos en la Convención Americana sobre Derechos Humanos, pero sí entiende que, aun no siendo un criterio de decisión sobre la prueba exigible a partir de la Convención, sí es compatible con la misma.

8 Es muy claro al respecto el art. 8, cuyo párrafo primero establece que «Toda persona tiene derecho a ser oída, con las debidas garantías y dentro de un plazo razonable, por un juez o tribunal competente, independiente e imparcial, establecido con anterioridad por la ley, en la sustanciación de cualquier acusación penal formulada contra ella, o para la determinación de sus derechos y obligaciones de orden civil, laboral, fiscal o de cualquier otro carácter».

9 En este punto la sentencia es un tanto enigmática, por cuanto reconoce que ha sido el inculpado «el destinatario originario de toda la arquitectura ilustrada que procuraba poner coto al avance del poder punitivo del Estado» (párr. 218), a pesar de lo cual recuerda que las garantías del artículo 8.1. de la Convención salvaguardan también «en casos como el presente (...), los derechos de acceso a la justicia de la víctima de un delito o de sus familiares y a conocer la verdad de los familiares» (párr. 218. La cursiva es mía). Pero, ¿a qué se hace referencia con la acotación «en casos como el presente»? ¿No debieran ser más bien garantías que se reconozcan para todos los sujetos procesales en cualquier procedimiento? 
Para analizar este punto, debemos partir de las dos grandes concepciones sobre la prueba que pueden registrarse tanto desde el punto de vista histórico como teórico: la concepción persuasiva (o subjetivista) y la concepción racional.

El punto de partida de ambas concepciones es la respuesta a la pregunta acerca del significado de "está probado que 'p'»: ¿qué decimos, o qué dice un juez, cuando formula en su decisión que un hecho está probado? Pues bien, la concepción persuasiva de la prueba responde que un enunciado de este tipo («Está probado que 'p'»), formulado como contenido de la decisión probatoria de un juez o de un jurado, significa que el decisor se convenció (i.e., adquirió la creencia sobre la ocurrencia del hecho 'p'). Es importante observar que, en la medida de que la convicción es un elemento subjetivo del decisor, si de ella depende conceptualmente que un hecho está probado en el proceso, entonces la decisión sobre la prueba (siempre que corresponda con las creencias sinceras del decisor) es infalible. Por otro lado, será perfectamente posible que dos jueces consideren que un hecho está probado y no probado, respectivamente, ante las mismas pruebas y no habrá posibilidad de afirmar que uno de ellos se equivoca. Volveré en un momento sobre este punto.

El segundo elemento que caracteriza la concepción persuasiva de la prueba es la asunción de una concepción fuerte del principio de inmediación. Dicho principio exigiría que el juzgador esté presente en la práctica de la prueba como un modo de que forme su convicción a partir de la impresión perceptiva que la prueba le cause. Pero el mismo principio tendría también una versión excluyente de la posibilidad de que cualquier otro sujeto que no haya tenido inmediación con la práctica de la prueba pueda valorarla o revisar por vía de recurso ${ }^{10}$.

La tercera característica de esta concepción es la ausencia de recursos en materia probatoria, entendidos en sentido estricto como la revisión por un tribunal superior de la corrección de la valoración de la prueba y la decisión sobre los hechos ${ }^{11}$. Es claro que si, conceptualmente, no hay posibilidad de error en la decisión probatoria de primera instancia, entonces no tiene sentido que el sistema prevea la posibilidad de formular recursos para la revisión de una decisión que es, por definición, correcta.

Finalmente, la concepción persuasiva de la prueba está vinculada con la ausencia de motivación sobre la decisión acerca de los hechos probados. Es claro que la ausencia de recursos y la infalibilidad de esa decisión debilitan o anulan la función endoprocesal de la motivación. Pero, más allá de ello, quedan razones de índole conceptual que hacen inviable la exigencia de motivación. Como expondré con algo

10 La Sala Penal del Tribunal Supremo español viene asumiendo últimamente la concepción persuasiva o subjetivista de la prueba. Es claro, por ejemplo en la Sentencia 532/2019, de 4 de noviembre (ponente: Vicente Magro Servet), en la que formula también una serie de 20 criterios más que discutibles para la valoración de la prueba indiciara. En relación con el principio de inmediación, la asunción de nuevo de una versión subjetivista es también clara, incluso en sentencias de la misma ponencia. Basta ver, por ejemplo, la STS 282/2018 y las indicaciones que allí se dan sobre la valoración de la prueba testifical y de la inmediación, que no se condicen en lo más mínimo con el conocimiento ya asentado en psicología del testimonio.

11 No sería propiamente un «recurso», en este sentido, la repetición del juicio en segunda instancia. 
más de detalle en el epígrafe 5.2., la motivación puede entenderse como justificación de las razones de la decisión o como explicación de los motivos de esta. Explicar y justificar, son obviamente, cosas muy distintas. Sucede, sin embargo, que el acto de creer que 'p' ocurrió es un acto involuntario. No podemos decidir voluntariamente nuestras creencias ${ }^{12}$. Y dado que solo se puede predicar justificación (o su injustificación) de los actos voluntarios, entonces tener la creencia de que p no puede ser objeto de justificación ${ }^{13}$. Queda la posibilidad de entender la motivación como explicación de los motivos que han llevado a tener la creencia. Más allá, sin embargo, de que una explicación de ese tipo no tiene el menor interés para las funciones de la motivación que he presentado, sucede que el funcionamiento de nuestro cerebro en el proceso de adquisición de creencias es, a día de hoy, opaco a nosotros mismos: solo muy superficialmente podemos explicar qué nos ha llevado a tener una creencia y, a veces, no somos capaces de hacerlo en absoluto. En ese proceso intervienen nuestro background, nuestras experiencias vitales, nuestros prejuicios y sesgos, nuestra ideología, etc., en un modo que no somos capaces de reconstruir. Por ello, si «está probado que 'p'» significa que el juzgador se convenció (adquirió la creencia) de que 'p', entonces no tiene sentido exigir motivación ni como explicación ni como justificación.

La concepción racional de la prueba, en cambio, se puede caracterizar por cuatro elementos que son, cada uno de ellos, antitéticos a los que acabamos de presentar. A la pregunta conceptual acerca de qué significa "Está probado que 'p'", la concepción racional de la prueba responde que «las pruebas presentadas aportan corroboración suficiente a la hipótesis de que 'p'». La noción de corroboración de hipótesis no es simple, pero sea como sea que se entienda, hace referencia al grado en que las pruebas confirman la hipótesis y no a elemento subjetivo alguno que ocurra en la mente del decisor. La corroboración es, pues, intersubjetivamente controlable.

El segundo elemento de la concepción racionalista de la prueba es la asunción de una versión débil del principio de inmediación. Así, se sostiene que la exigencia de que el juzgador esté presente en la práctica de la prueba se justifica en la reducción de errores (puesto que cuantos más intermediarios haya mayor será la probabilidad de que la información se deforme a cada paso) y en posibilitar la participación del propio juzgador en la práctica de la prueba en contradicción. Pero la inmediación no otorga ninguna prioridad a la decisión del juzgador de primera instancia ni impide el control de su razonamiento por tribunales superiores ${ }^{14}$.

La tercera característica de esta concepción es la previsión de recursos sobre la decisión probatoria, entendidos como control del razonamiento sobre los hechos, ahora ya no impedido por la versión fuerte del principio de inmediación. Además,

12 Puede verse este argumento con mayor detalle en Ferrer Beltrán, 2002: 85 ss.

13 Adviértase que la justificación del acto de tener una creencia y la justificación del contenido proposicional de una creencia son cosas muy distintas. Lo primero es un sinsentido, mientras que lo segundo es perfectamente posible. Ahora bien, la justificación del contenido proposicional de una creencia ya no es dependiente de que un sujeto u otro tenga la creencia y, en ese sentido, ya no tiene carácter subjetivo.

14 Véanse, por todos, al respecto, ANDrÉs IBÁÑEz, 2003: I 53 ss. y ANDRÉs IBÁÑEz, 2015: 272 ss. 
esos recursos se hacen posibles por la exigencia de una rigurosa motivación (cuarta característica) en materia de hechos, entendida como justificación a la luz de las pruebas presentadas y practicadas de que la hipótesis alcanza o no el grado de corroboración suficiente establecido por el estándar de prueba aplicable al caso.

Las dos concepciones sobre la prueba, persuasiva o subjetivista y racional, tienen una perfecta coherencia interna, pero no pueden ser mezcladas sin que la coherencia se pierda. No tiene sentido, por ejemplo, partir de la prueba como íntima convicción y exigir motivación o prever la posibilidad o incluso el derecho de recurrir las decisiones probatorias. Sucede, sin embargo, que nuestros legisladores y tribunales no siempre son conscientes de esa incompatibilidad y parece que la Corte ha caído también en la trampa de la confusión conceptual: ¿qué sentido tiene la doctrina del derecho al doble conforme, por ejemplo, si se parte de una concepción de la prueba que no admite la posibilidad conceptual de decisiones erróneas?, ¿qué espacio queda para la exigencia de motivación si se asume el punto de partida de una concepción persuasiva de la prueba? En realidad, puede verse como todo el embrollo en que la Corte se mete para dar cuenta de una mínima exigencia de motivación para los jurados proviene, precisamente, de estas confusiones.

En lo que sí tiene razón la Corte es en su afirmación de que, si el criterio de decisión sobre los hechos es la íntima convicción, "[l]a libre valoración que hace el jurado no es sustancialmente diferente de la que puede hacer un juez técnico» (párr. 262). Pero no porque ese criterio no sea arbitrario, como sostiene la Corte, sino porque lo es en todo caso, con independencia de quien sea el juzgador. Lo muestra con claridad una sentencia del Tribunal Constitucional español, emitida en atención de un recurso de amparo presentado contra una sentencia condenatoria de un tribunal de apelación por una supuesta violación del derecho a la presunción de inocencia ${ }^{15}$. Dice el Tribunal (STC 124/1983, F.J. 10):

Por otra parte, conviene también señalar aquí que el razonamiento del Juez de Instrucción de Noya contenido con el considerando primero de su Sentencia es impecable desde el punto de vista constitucional, esto es, bajo el enfoque del art. 24.2 de la C.E., pues si a él, bajo el sistema de libre apreciación de la prueba del art. 741 de la Ley de Enjuiciamiento Criminal, las pruebas practicadas no le convencieron de la culpabilidad de los encartados, actuó perfectamente al absolverlos, porque bajo el imperativo del art. 24.2 de la C.E. es evidente que nadie puede ser condenado sólo porque «existan indicios que apunten hacia la posible participación» del o de los acusados en los hechos delictivos. Sucede, sin embargo, que si con los mismos elementos probatorios otro Tribunal, el de apelación, «apreciando según su conciencia las pruebas practicadas en el juicio» (art. 741 de la Ley de Enjuiciamiento Criminal) llega a un resultado contrario, y en este caso, al convencimiento razonable y razonado de la culpabilidad de los antes absueltos, no por ello puede afirmarse violación alguna contra la presunción de inocencia, siempre que las pruebas practicadas en el juicio sean las que le proporcionen fundamento para su convicción. Así las

15 En el caso que dio origen al amparo, el imputado por un pequeño tráfico de drogas había sido absuelto en primera instancia por insuficiencia de la prueba y, posteriormente, con las mismas pruebas, condenado en segunda instancia. Su defensa recurrió entonces en amparo ante el Tribunal Constitucional alegando que las pruebas de cargo eran insuficientes para derrotar la presunción de inocencia, de modo que la condena de segunda instancia violaba ese derecho. 
cosas, no puede hablarse de vulneración de la presunción de inocencia, sino de una discrepancia en la valoración de la prueba hecha por dos órganos judiciales igualmente libres para valorar en conciencia, con el resultado de que entre ambas valoraciones ha de imponerse la del Tribunal de apelación.

Es decir, con las mismas pruebas, tan impecable es condenar como absolver. No hay nada que decir, porque siendo el criterio de decisión sobre los hechos la valoración en conciencia (o la íntima convicción, que es lo mismo), ambos juzgadores actuaron perfectamente al seguir su conciencia o convicción y, haciéndolo, no hay posibilidad conceptual de error en la valoración de la prueba. Lo que no tiene sentido es que si no hay posibilidad de error, el sistema habilite el recurso contra la decisión. Ahora bien, si con los mismos elementos de juicio tan impecable es hacer una cosa como su contraria, decidir por cualquiera de ellas es un caso paradigmático de arbitrariedad.

La búsqueda de la verdad es un elemento imprescindible para un proceso garantista de los derechos ${ }^{16}$. Es por ello que el descubrimiento de la verdad es, y no puede dejar de ser, un objetivo estructural de la actividad probatoria en todo proceso ${ }^{17}$. Siendo así, es imperativo preguntarse cuál de las concepciones sobre la prueba, persuasiva o racional, es la adecuada para satisfacer ese objetivo. La respuesta es evidente: las creencias o convicciones del juzgador (punto de partida de la concepción persuasiva) no son un indicador de la verdad de lo creído. La suficiencia de la corroboración, en cambio (punto de partida de la concepción racional de la prueba) no es garantía de la verdad de lo corroborado, pero sí de que cuenta con una probabilidad suficiente de serlo. Corresponde al legislador diseńar el proceso penal, pero un sistema procesal penal basado en la íntima convicción es incompatible con el derecho al debido proceso y con la interdicción de la arbitrariedad.

Es pacífico a día de hoy considerar que el derecho a la prueba es parte integrante de las garantías del debido proceso. En realidad, se trata de un derecho poliédrico que integra otros derechos más específicos ${ }^{18}$, en concreto: $a$ ) el derecho a presentar y a que sean admitidas todas las pruebas relevantes de que se disponga; $b$ ) el derecho a que las pruebas presentadas y admitidas sean debidamente practicadas; $c$ ) el derecho a que las pruebas presentadas, admitidas y practicadas sean racionalmente valoradas; y finalmente, $d$ ) el derecho a una decisión motivada sobre los hechos. Dejaré este último punto para el epígrafe 5.3 de este trabajo, pero conviene, en cambio, seńalar ahora que resultaría totalmente inútil reconocer el derecho a presentar y practicar las pruebas relevantes de que se disponga para sostener las alegaciones de las partes si luego esas pruebas pudieran valorarse arbitrariamente (o considerar tan impecable

16 No es este el lugar para desarrollar los argumentos que lo justifican, pero puede encontrarse una presentación detallada de los mismos en Ferrer Beltrán, 2002: 55 ss. Véase también, al respecto, Ferrajoli, I 998: 619 ss. y 639 ss.

17 Lo que no quiere decir que sea el único objetivo del proceso ni que, en caso de conflicto con otros objetivos, no pueda también ceder.

18 Para una exposición razonada y detallada, me remito a Ferrer Beltrán, 2003: 28 ss. 
concluir a partir de ellas una cosa y su contraria, con tal de que se afirme que el juzgador se convenció).

\section{2. La concepción de la motivación}

Hay en el mercado de las ideas dos grandes concepciones de la motivación de las decisiones judiciales, que podemos también denominar "psicologista» y «racionalista» ${ }^{19}$. La primera de ellas identifica a la motivación con la expresión lingüística de los motivos que han llevado a una decisión. La segunda, en cambio, entiende la motivación como justificación: una decisión motivada sería, entonces, una decisión que cuenta con razones que la justifican. Las dos concepciones cuentan con el apoyo lingüístico de la ambigüedad del término «motivar», que denota tanto la expresión de los motivos como de las razones de una decisión ${ }^{20}$. Pero ambas cosas no deben ser confundidas ${ }^{21}$.

El realismo jurídico, especialmente el norteamericano, puso especial atención a los mecanismos causales que motivan las decisiones judiciales, señalando que, entre ellos, las normas generales no ocupan el único lugar ni tan siquiera un lugar privilegiado. Las causas que motivan la decisión de un juez incluyen su ideología, contexto social, estado de ánimo, prejuicios, cultura jurídica, etc., del mismo modo que ocurre con las decisiones ordinarias que tomamos cada uno de nosotros. Los realistas, por ello, destacaron la necesidad de estudiar estos factores sociológicos como método adecuado para poder predecir las decisiones judiciales, i.e., a su entender, conocer el derecho vigente.

Un enunciado que afirma que $c$ es una de las causas de la decisión o conducta humana es, desde luego, un enunciado descriptivo y, en consecuencia, verdadero o falso. Por ello, la motivación concebida como expresión de los motivos (las causas) de una decisión es un discurso lingüístico descriptivo. Como tal, no es capaz de justificar la decisión, puesto que la justificación pertenece al ámbito de lo normativo y no hay salto posible que permita fundar una conclusión normativa en un conjunto de premisas descriptivas. Con ellas podremos entender, como máximo, qué llevó al juez a decidir como decidió, pero no aportará nada a la justificación de su decisión. No es extraño pues que, en general, los realistas no hayan puesto el acento en la necesidad de que el juez motive sus decisiones, sino en que la sociología del derecho estudie los

19 Véase Colomer Hernández, 2003: 31 ss. Las concepciones psicologista y racionalista de la motivación están fuertemente emparentadas, pero no deben ser confundidas, con las concepciones de la prueba que he denominado en el epígrafe anterior persuasiva o subjetivista y racionalista. Están emparentadas porque quien sostiene la concepción subjetivista de la prueba, es común que sostenga una concepción psicologista de la motivación, por ejemplo. Pero no deben confundirse con ellas porque la motivación no se agota en los aspectos probatorios de la decisión judicial.

20 Véase, entre otros muchos, Igartua, 2003: 61 ss. y Aliste, 2018: 435 ss.

21 La distinción entre motivos y razones es considerada por Nino, precisamente, una distinción fundamental de la filosofía analítica. Véase Nino, 1993: p. 37. 
factores causales que llevan a esas decisiones ${ }^{22}$. Entendida de este modo, resultaría, por ejemplo, que la Constitución española impondría a los jueces y tribunales expresar en sus sentencias las motivaciones causales que les llevan a tomar sus decisiones jurisdiccionales. Dado que entre estas motivaciones habrá factores de lo más diversos (que van desde sus traumas infantiles a la presión mediática, desde su ideología a la cultura jurídica adquirida), no se entiende bien qué relevancia social y jurídica tendría para que su expresa formulación fuera exigida constitucionalmente.

En todo caso, ningún iusrealista fue escéptico solo respecto de los hechos en el proceso judicial. Es más, lo fueron especialmente respecto de la capacidad motivadora de las normas generales. Sin embargo, en el último siglo ha sido muy habitual entre los juristas prácticos y entre los estudiosos del derecho procesal una curiosa combinación de formalismo respecto de las normas y escepticismo respecto de las posibilidades de alcanzar conocimiento de los hechos mediante la prueba en el proceso judicial. Y, llegados al tema de la motivación, se combinan fuertes exigencias de motivación (entendida como justificación) por lo que respecta a las premisas normativas del razonamiento, la quaestio iuris, y débiles o inexistentes exigencias de motivación (entendida ahora como expresión del iter mental, de los factores causales de la decisión) por lo que concierne a las premisas fácticas, la quaestio facti 23. Sirva como muestra lo que afirma De la Oliva (2002: 5 I 4):

22 Una excepción a la poca atención prestada a la motivación de las decisiones por parte del movimiento iusrealista es la obra de Frank (1930: 123 ss. y 159 ss.). Al respecto, creo especialmente oportunas las consideraciones de Taruffo: «una sugerencia de este tipo resulta incongruente tanto en el orden de ideas que profesa el autor que la propone, como en línea de máxima y también fuera de est[e]. Desde el primer punto de vista, es absurdo exigir que la motivación refleje los procesos psíquicos del juez, después de haber subrayado con extrema decisión precisamente los múltiples elementos de irracionalidad, de ambigüedad y también de falta de control de tales procesos (...). Desde el segundo punto de vista, la sugerencia es también absurda, porque la manera en que [e]sta puede concretizarse es imposible: el juez no puede (y aunque pudiera sería probablemente inoportuno) recorrer en un sentido inverso las etapas de un proceso psíquico que, como tal, le es en gran medida desconocido en sus componentes decisivos; por otra parte, una hipotética motivación de este tipo sería inútil, dado que no tiene sentido hablar de control de validez y de rectitud del proceso psíquico a través del cual el juez llegó a la decisión» (Taruffo, 2006: 97, nota 55.). El absurdo de las exigencias de Frank señalado por Taruffo depende, en realidad, del objetivo con el que se impongan las exigencias de motivación. Desde luego, si el objetivo declarado es permitir el control por las partes y por tribunales superiores de la correcta aplicación del derecho, este no tiene ningún sentido si se declara que las decisiones judiciales son solo el resultado causal de múltiples factores sociales y personales. De ser así, el tribunal superior solo podría decir sensatamente «mi convicción es otra y yo mando más», pero para esto no es necesario analizar motivación alguna del tribunal inferior.

23 Desarrollando la obligación constitucional de motivar las sentencias, formulada en el artículo 120.3 de la Constitución española, el Tribunal Constitucional español ha sostenido la necesidad de que «el órgano judicial explicite el iter mental que le ha llevado a entender probados los hechos constitutivos del delito" (véase STC 229/1988). En mi entender, la formulación no puede ser más clara ni más equivocada como forma de entender la garantía constitucional de la motivación. Un año después, el mismo Tribunal Constitucional consideró (STC 217/1989) intrínseco a la inmediación y la libre valoración de la prueba «el examinar gestos de los intervinientes en la misma, tales como la turbación o la sorpresa, a través de los cuales pueda el Juez o Tribunal de instancia fundar su íntima convicción acerca de la veracidad o mendacidad de la declaración (...), con respecto a los cuales el juzgador de instancia es dueño de 
no es exigible, ni legal ni racionalmente, que toda sentencia dé cuenta detallada del porqué de cada declaración de certeza positiva de un hecho (eso es la declaración de «hecho probado») (y, en su caso, muy raro pero posible, de las declaraciones de certeza negativa: certeza de la inexistencia de un hecho): no es tampoco legal ni racionalmente exigible que se explique pormenorizadamente por qué unos hechos han sido considerados dudosos («no probados») pese al esfuerzo probatorio que haya podido desplegarse. No es razonable imponer a los órganos jurisdiccionales unos esfuerzos expresivos máximos, en cada sentencia, que desconozcan la carga de trabajo (...) que sobre ellos pesa y que resulten contrarios a impartir justicia a todos de manera satisfactoria. Y tampoco parece razonable pedir que se exprese lo que pertenece a los internos procesos psicológicos de convicción, muchas veces parcialmente objetivables, sí, pero también parcialmente pertenecientes al ámbito de lo inefable.

Si dejamos a un lado el problema de la carga de trabajo de los jueces (cuya solución bien pudiera ser otra que no fuera la de eliminar las exigencias de motivación), lo que queda del argumento de De la Oliva es la parcial inaccesibilidad de los motivos de las decisiones, incluso para el propio juez que adopta la decisión. Si motivar es expresar lingüísticamente los motivos, los factores que han causado la decisión, habrá que dar cuenta del iter mental que ha llevado al juez al convencimiento respecto de los hechos (y de las normas, añadiría yo). Pero los factores causales de nuestras creencias nos resultan (parcialmente) inaccesibles ${ }^{24}$. Solo somos capaces de describir algunas de las más inmediatas circunstancias que nos llevan a adquirir una creencia, pero, desde luego, esta descripción, aún hecha concienzudamente, no sería más que limitada y muy parcial respecto de las causas de la decisión ${ }^{25}$. En resumen, como he argumentado en el epígrafe anterior, si se vincula la prueba con las creencias subjetivas del decisor, la exigencia de motivación resulta inútil (por lo que hace a sus funciones) y de imposible cumplimiento.

Frente a la concepción analizada hasta aquí, la concepción racionalista de la motivación entiende a ésta última como justificación de la decisión judicial. Así, para esta concepción, decir que una sentencia está motivada significa que está debidamente justificada ${ }^{26}$. Ahora bien, de nuevo aquí se abren dos posibilidades: en primer lugar,

su valoración». Tampoco aquí puede decirse que la concepción de la valoración de la prueba que asume el Tribunal Constitucional español sea muy garantista: se trata, de forma coherente con la concepción de la motivación, de una concepción psicologista o persuasiva difícilmente conciliable, como ya he argumentado, con garantías constitucionales como la interdicción de la arbitrariedad, la presunción de inocencia en el ámbito penal, etc. Al respecto, véase también GaSCón ABELLÁN: 211-2.

${ }^{24} \mathrm{Y}$ en caso de órganos colegiados, como los jurados, resulta, además, especialmente complicado: ¿habrá que describir los factores causales que han llevado a la decisión de cada uno de los magistrados o los miembros del jurado? Evidentemente, los motivos de las convicciones de cada uno de ellos pueden ser distintos, de manera que resultaría necesario expresarlos todos ellos.

${ }_{25}$ Sobre estas dificultades, puede verse, por todos, TARUfFo, 2006: 110 ss.

26 Entre muchos otros, es muy claro en este sentido Bergholtz, quien afirma que: «En esta perspectiva (...), cómo se generaron realmente las razones dadas y si estas son las razones reales del juez, adquiere una importancia relativamente menor. Así, si las razones dadas están bien fundadas y son válidas no importa si son o no las razones "reales" del juez». (Bergholtz, 1990: 85). Resulta también evidente la ambigüedad del término «razones” en la cita de Bergholtz: unas veces sinónimo de «motivos” "«las razones reales del juez") otras como elementos con fuerza justificatoria. Véase también Ferrajoli, 1998: 38 ss.; AtienZa, 2003: 6-7; y Nieto, 2000: 157, donde afirma que «el juez ni debe ni puede "explicar" 
una decisión puede considerarse justificada si hay razones suficientes que la funden; o, en segundo lugar, puede considerarse justificada no solo si hay tales razones, sino, además, si esas razones han sido formuladas lingüísticamente (i.e., expresadas en la sentencia) de modo analítico ${ }^{27}$. En otras palabras, se trata de distinguir entre tener razones para $x$ y dar razones para $x 28$. Es claramente esta última la forma en la que entiende la obligación de motivar la Corte cuando afirma que la motivación «es la exteriorización de la justificación razonada que permite llegar a una conclusión y conlleva una exposición racional de las razones que llevan al juzgador a adoptar la decisión» (párr. 254). De este modo, la motivación de la sentencia sería la expresión lingüística de las razones que justifican la decisión adoptada ${ }^{29}$. En cambio, la Corte parece asumir la concepción de la motivación como existencia de razones justificativas (aunque no hayan sido expresadas), cuando afirma que para que el veredicto del jurado cumpla con la obligación de estar motivado «el veredicto debe permitir que, a la luz de las pruebas y el debate en audiencia, quien lo valora pueda reconstruir el curso lógico de la decisión de los jurados, quienes habrían incurrido en arbitrariedad en el supuesto en que esta reconstrucción no fuera viable conforme a pautas racionales» (párr. 259). Y, para rizar el rizo de la confusión, solo bajo la concepción psicologista de la motivación (referente a los motivos, no a las razones), puede afirmarse que "todo veredicto siempre tiene motivación", como también hace la propia Corte (párr. 259), dado que es evidente que no todo veredicto está justificado, pero sí causado por algún motivo.

Más allá de las evidentes inconsistencias respecto de la concepción de la motivación asumida por la Corte en la sentencia analizada, conviene preguntarse si es posible respecto de un veredicto en el que no se expresen las razones que lo justifiquen, «reconstruir el curso lógico de la decisión de los jurados». Veamos un ejemplo no jurídico: imaginemos que Pedro debe tomar una decisión basada en la regla «si hay elementos suficientes para estimar que llueve o que lloverá en los próximos minutos, cierre la ventada». Conocemos que en el momento en que Pedro toma la decisión disponía de información meteorológica fiable y que Pedro decidió cerrar la ventada. Aun cuando Pedro no haya expresado las razones que justificarían su decisión, podemos reconstruir el razonamiento justificativo (que no tiene por qué coincidir con el motivacional), porque conocemos los hechos (la información meteorológica de la que disponía), la regla aplicable («si hay elementos suficientes para estimar que llueve o que lloverá en los próximos minutos, cierre la ventada») y la decisión (cerrar la ventana). Podemos hacerlo porque todos los elementos del razonamiento,

\footnotetext{
los motivos psicológicos de su decisión (de los que con frecuencia ni él mismo es consciente), la ley no se lo exige ni tendría utilidad alguna para las partes. Lo que importa -y lo que es legalmente exigible- es la motivación en el contexto de justificación, es decir, el razonamiento que justifica que la decisión es admisible dentro de los conocimientos y reglas del Derecho».

27 Sobre la distinción entre el modo analítico y el holista de motivar o justificar una decisión, véase TARUFFo, 1992: 307 ss.

$28 \mathrm{Al}$ respecto, véase Schauer, 2009: 175 ss.

29 Afirma TARuffo (2010: 37), en este sentido, que «la motivación es (...) un discurso justificativo constituido por argumentos racionales».
} 
premisas y conclusión, son constatables y controlables intersubjetivamente. ¿Es esta la situación en que nos encontramos ante un veredicto inmotivado? La respuesta es que depende. ¿Conocemos la regla procesal que gobierna la decisión del jurado acerca de los hechos? En el caso del jurado nicaragüense, sí. Su Código de Instrucción Criminal (al igual que el vigente Código Procesal Penal) establece que procederá declarar probados los hechos de los que se acuse al imputado si el jurado alcanza la íntima convicción de que estos se produjeron. Pues bien, dado que el criterio para la toma de decisión es netamente subjetivo (la convicción de cada decisor), resulta claramente imposible reconstruir por parte de otro sujeto que no sea el propio decisor las supuestas razones que justificarían su decisión.

Plantearé el punto desde otra perspectiva. Dado que en todo estado de derecho el proceso penal debe estar regido por la presunción de inocencia (reconocido como derecho en el art. 8.2 de la Convención Americana sobre Derechos Humanos), necesitamos saber en qué condiciones podrá estimarse derrotada la presunción o, en otros términos, cuándo la hipótesis acusatoria estará suficientemente corroborada para considerarla probada. Esta es precisamente la función de un estándar de prueba: determinar el umbral de exigencia probatoria para que una hipótesis se considere probada. Pero el umbral no es necesariamente único: una misma hipótesis, con las mismas pruebas y el mismo grado de corroboración puede estimarse probada si el estándar de prueba es X y no probada si es X + 1. Esto explica, por ejemplo, que las mismas pruebas puedan ser suficientes para considerar probado un hecho en un proceso civil e insuficientes para un proceso penal. Para que una decisión sobre la prueba de la hipótesis $\mathrm{H}$ esté justificada debemos mostrar que las pruebas disponibles otorgan a $\mathrm{H}$ un cierto grado de corroboración y que ese grado de corroboración es suficiente de acuerdo con el estándar de prueba aplicable. Ahora bien, si no conocemos el estándar de prueba aplicable o éste resulta indeterminado, no hay forma de justificar que la corroboración es suficiente. Sin estándar de prueba no hay motivación posible (entendida como justificación) ${ }^{30}$.

Es por esto que LAUDAN ha mostrado con acierto que cualquier fórmula o criterio de decisión que apele a elementos psicológicos o mentales del decisor (como la «íntima convicción», la "certeza subjetiva», la "valoración en conciencia», etc.) no permite el control intersubjetivo de la justificación de la decisión y, por tanto, no son aptos para facilitar la revisión de la corrección de la misma ni para dar garantías, por ejemplo, del cumplimiento de la presunción de inocencia en el proceso penal ${ }^{31}$.

$30 \mathrm{Y}$ tampoco hay posibilidad de determinar si se ha respetado o se ha violado la presunción de inocencia, porque se desconoce cuál es el umbral de suficiencia probatoria para derrotarla.

31 Véase Laudan, 2005: 99 ss. Lo mismo sucede, por cierto, si se dan interpretaciones subjetivistas a otro tipo de fórmulas (por demás indeterminadas) como el «más allá de toda duda razonable» (i.e., si no tenemos más criterio de razonabilidad de la duda que la convicción del decisor). Al respecto, véase un clarificador análisis en LAUDAN, 2003; también en Id., 2006: 59-102. Sobre la interpretación en Inglaterra, véase RoBERTS y ZuCKERMAN, 2004: 361 ss. Una presentación de los requisitos que deberían cumplirse para la formulación adecuada de un estándar de prueba puede verse en FerRer Beltrán, 2018: 403 ss. 
En definitiva, contra lo que afirma la Corte, una decisión inmotivada basada en un criterio subjetivo como la íntima convicción no hace posible en ningún caso la reconstrucción del razonamiento justificativo.

\subsection{El contenido de la motivación}

Dejé pendiente en el epígrafe 5.1 el problema de la incompatibilidad entre una regulación que exima del deber de motivación al decisor (sea jurado o juez profesional) y las exigencias del derecho a la prueba. Hemos visto ya que uno de los elementos que conforman el derecho a la prueba es el derecho a una resolución probatoria motivada, pues solo a través de ella puede controlarse su validez. Hay que decir ahora que aquí "motivada» hace referencia a que en la resolución se expresen las razones en que se funda o, en otros términos, la valoración de la prueba realizada y el estándar de prueba aplicado.

Demasiadas veces se confunde la motivación con la descripción de las pruebas admitidas y lo ocurrido en la audiencia durante la práctica de la prueba. Ello, claro está, no cumple con las exigencias de una concepción racional de la motivación como justificación de la decisión. El contenido de la motivación, en cambio, puede ser descompuesto en cuatro partes, que operan como tres premisas y una conclusión: 1) el análisis de cada una de las pruebas y la justificación de la fiabilidad otorgada a cada una de ellas (valoración individual de la prueba); 2) la valoración de conjunto de las pruebas a los efectos de determinar y justificar el grado de corroboración que estas otorguen a cada una de las hipótesis fácticas en conflicto en el proceso; 3) la identificación del estándar de prueba aplicable a ese tipo de proceso y a la concreta decisión procesal que se esté adoptando (una medida cautelar, la apertura de juicio, la sentencia, etc.); y 4) la conclusión acerca de si, a la luz de las pruebas disponibles y el estándar de prueba aplicable, alguna de las hipótesis fácticas debe ser declarada como probada. Por supuesto, no solo hay que justificar la declaración de una hipótesis como probada sino también la conclusión de que una hipótesis no alcanza el grado de corroboración suficiente para declararla probada en atención al estándar de prueba que sea aplicable al caso.

Cada una de las partes 1 a 3, identificadas en el párrafo anterior, estará a su vez compuesta de una cadena inferencial, con conclusiones parciales que operan a su vez como premisas del siguiente paso argumental ${ }^{32}$.

32 Sobre el razonamiento probatorio como cadena de inferencias, véase Hernández Marín, 2018: 69 ss. Por otra parte, la necesidad de apelar a una regla, el estándar de prueba, para poder extraer conclusiones acerca de si una hipótesis está probada o no es una razón, adicional a otras, para poner en cuestión la distinción neta entre quaestio facti y quaestio juris. 


\subsection{Razonamiento probatorio y jurado}

Inicié el epígrafe 4 de este trabajo, calificando la argumentación de la Corte contra la alegada violación del debido proceso por falta de motivación en las decisiones del jurado nicaragüense como un ejercicio de realpolitik. Solo así se entiende que la sentencia dedique espacio a consideraciones irrelevantes para el juicio de compatibilidad entre la legislación procesal nicaragüense y la Convención Americana sobre Derechos Humanos, como el número de estados firmantes de la Convención en los que existe el juicio por jurados. Parece estar implícito que si se sostenía la inconvencionalidad de las decisiones inmotivadas por íntima convicción se seguiría la inconvencionalidad del jurado, lo que habría tenido un impacto enorme, dado el número de estados que tienen la figura y la tendencia más bien a su ampliación. De ahí también las consideraciones de la Corte de que "corresponde a la esencia del jurado" tomar decisiones en las que no se exprese la motivación (párr. 259). Ahora bien, jes esto así? ¿no hay posibilidad de exigir de los jurados una decisión motivada, esto es, una justificación analítica de su veredicto? En principio, no hay nada que haga imposible el cumplimiento de una exigencia de ese tipo, pero veámoslo con más calma.

Algunos países, como España, han dispuesto en su regulación sobre el jurado que este deberá motivar su veredicto. Así, el art. 61.1 de la Ley 5/1995, Orgánica del Tribunal del Jurado, dispone que en el acta en la que deberá redactarse el veredicto, tendrá que incluirse:

Un cuarto apartado, iniciado de la siguiente forma: 'Los jurados han atendido como elementos de convicción para hacer las precedentes declaraciones a los siguientes: .... Este apartado contendrá una sucinta explicación de las razones por las que han declarado o rechazado declarar determinados hechos como probados.

Vale la pena señalar que es precisamente la previsión de esa «sucinta explicación» lo que ha hecho que el Tribunal Europeo de Derechos Humanos considere compatible esta regulación con las exigencias del art. 6.1 del Convenio Europeo de Derechos Humanos ${ }^{33}$. Sin embargo, conviene recordar también que la decisión sobre los hechos en Espańa, ya sea tomada por un juez profesional o un jurado, se adopta a partir de la valoración en conciencia de la prueba (art. 741.1 de la Ley de Enjuiciamiento Criminal) y que, como acertadamente ha señalado críticamente Aliste Santos (2018: 435 ss.), el art. 6I.I de la Ley del Tribunal del Jurado exige una explicación y no una justificación del veredicto. Estamos, pues, de nuevo, ante una concepción persuasiva de la prueba y una concepción psicologista de la motivación, que no supone un genuino avance hacia el respeto del debido proceso y del derecho a una decisión motivada (justificada) sobre los hechos ${ }^{34}$.

33 Así es en la STEDH Bellerin Lagares vs. España, de 16 de noviembre de 2010 y, de forma análoga, se resuelve también en el caso Judge vs. Reino Unido, en STEDH de 8 de febrero de 2011.

34 En el mismo sentido, Igartua Salaverría, 2000: 56. Andrés IbáŃEz (2004: 282), por su parte, considera que «es patente que se ha llegado a establecer dos distintos estándares de exigencia, uno de ellos, el relativo al jurado, de muy bajo perfil, que, en muchos casos, se ha dado por cumplido con la 
La pregunta, pues, permanece todavía sin respuesta: ¿se puede exigir a los jurados legos que justifiquen adecuadamente sus decisiones sobre los hechos? La respuesta dependerá del tipo de formación que estimemos necesaria para realizar un correcto razonamiento probatorio, que conduzca a la adopción de decisiones justificadas. En mi opinión, esa formación debe incluir, como mínimo, conocimientos de epistemología y lógica elemental, así como una buena comprensión de los problemas relativos a la prueba pericial (y un conocimiento básico sobre los distintos tipos de pruebas periciales más habituales en el proceso) y de los avances en psicología del testimonio. No me cabe la menor duda que muchos jueces profesionales carecen de esa formación (y lamentablemente, algunas sentencias incluso de Altos Tribunales nacionales e internacionales son buena muestra de ello). Pero dado el carácter de repeat players de los jueces profesionales es posible diseñar capacitaciones que les den esos conocimientos. En cambio, no parece posible dar esa formación a personas que solo intervendrán una vez en la tarea de juzgar los hechos ${ }^{35}$. Confiar en el juicio por jurados, a fin de cuentas, supone asumir una concepción persuasiva, subjetivista, sobre la prueba (como parece hacer la Corte en la sentencia comentada) o que desarrollar el tipo de razonamiento probatorio necesario para tomar decisiones justificadas sobre los hechos en un proceso y expresar analíticamente esa justificación no requiere formación previa alguna, lo que la experiencia nos ha demostrado falso (tanto en el caso de los jueces profesionales como en el de los jurados).

La Corte no necesitó ninguna de estas consideraciones para considerar violado también el derecho al debido proceso en el caso individual (párrs. 269-271). En cambio, estableció criterios generales sobre la exigencia de motivación que muestran una gran confusión respecto de las distintas concepciones de la motivación y que rebajan sustancialmente los requerimientos formulados en su jurisprudencia previa. Por lo que hace a la prueba, por su parte, validó sin matices la compatibilidad entre una regulación que incorpora la más rancia versión de la concepción persuasiva o subjetivista de la prueba con las garantías procesales reconocidas como derechos en la Convención Americana sobre Derechos Humanos. Todo ello con la finalidad de salvar la institución del jurado de las serias dudas sobre su convencionalidad ${ }^{36}$, perdiendo así una gran oportunidad para reafirmar la doctrina de la Corte sobre el debido proceso y las exigencias de motivación en relación con el jurado. Al decir de

mera indicación de las fuentes de prueba, y, en muchos otros, con alguna telegráfica referencia a los elementos de esta. Y todo, como único modo de evitar la reiteración de nulidades».

35 En el mismo sentido, Andrés IbÁÑez: 2004: 28 I ss. y Aliste Santos, 2018: 436 ss., donde se encuentran también interesantes indicaciones jurisprudenciales españolas en el mismo sentido. La Corte indica la posibilidad de introducir mecanismos que mitiguen la falta de capacitación de los jurados, como que un juez técnico lo instruya, que se formulen preguntas precisas al jurado o que se le ofrezca información experta que disminuya su propensión a decisiones basadas en sesgos o prejuicios (párrs. 264-5). ANDRÉs IBÁŃEZ (2004: 279-80) muestra, sobre la base de la experiencia española, su claro escepticismo frente a todas ellas: una adecuada formación en razonamiento probatorio no es algo que se pueda ofrecer en una tarde a personas no relacionadas con la materia.

36 Las mismas dudas que llevan a ANDRÉs IbáŃEz (2004: 283) a calificar eufemísticamente al jurado como una institución de «una constitucionalidad débil». 
Sagües (2018: 1): «la sensible divulgación del sistema de jurados, con perspectiva de aumento en nuestros días, conspira contra su fiscalización. Dicho de otro modo: cuanto más se adopte en Latinoamérica el jurado con veredicto inmotivado, más difícil será declararlo inconvencional».

\section{BIBLIOGRAFÍA}

Aliste Santos, T.J., 2018: La motivación de las resoluciones judiciales, 2a ed., Madrid: Marcial Pons.

ANDRÉs IBÁŃEZ, P., 1992: «Acerca de la motivación de los hechos en la sentencia penal», en Doxa, no 12. Citado por la edición incluida en Andrés IbáŃEz, P.: En torno a la jurisdicción, Buenos Aires: Ediciones del Puerto, 2007.

- 2003: «Sobre el valor de la inmediación (una aproximación crítica) », en Jueces para la Democracia, nº 46; citado a través de la edición contenida en ANDrÉs IbáŃEZ, P.: En torno a la jurisdicción, Buenos Aires: Ediciones del Puerto, 2007.

— 2004: «Jurado: el debate debe continuar», en AA.VV.: Juicio por jurado. Cuestiones teóricas y práctica, Madrid: Dykinson; citado por la publicación en ANDRÉs IbáŃEZ, P.: En torno a la jurisdicción, Buenos Aires: Ediciones del Puerto, 2007.

- 2015: Tercero en discordia. Jurisdicción y juez del estado constitucional, Madrid: Trotta.

Atienza, M., 2003: Las razones del derecho. Teorías de la argumentación jurídica, México D.F: UNAM.

Bergholtz, G., 1990: «Ratio et auctoritas: algunas reflexiones sobre la significación de las decisiones razonadas», en Doxa, núm. 8.

Castillo Alva, J.L., 20 13: La motivación de la valoración de la prueba en materia penal, Lima: Grijley.

Colomer hernández, I., 2003: La motivación de las sentencias: sus exigencias constitucionales y legales, Valencia: Tirant lo Blanch.

De la Oliva, A., 2002: «La sentencia», en De la Oliva, A., Aragoneses, S., Hinojosa, R., Muerza, J. y TомÉ, J.A.: Derecho procesal penal, $5^{\text {a }}$ ed., Madrid: Centro de Estudios Ramón Areces.

Ferrajoli, L., 1998: Diritto e ragione. Teoria del garantismo penale, Roma-Bari: Laterza.

Ferrer Beltrán, J., 2002: Prueba y verdad en el derecho, 2a ed. Madrid: Marcial Pons, 2005.

— 2003: «Derecho a la prueba y racionalidad de las decisiones», en Jueces para la Democracia, núm. 47.

— 2018: «Prolegómenos para una teoría de los estándares de prueba. El test case de la responsabilidad del estado por prisión preventiva errónea», en Papayannis, D.M. y Pereira Fredes, E. (eds.): Filosofia del derecho privado, Madrid: Marcial Pons.

Frank, J. 1930: Law and the Modern Mind, citado por la edición de New York: Anchor Books, 1963.

Gascón Abellán, M., 1999: Los hechos en el derecho. Bases argumentales de la prueba, Madrid: Marcial Pons.

Hernández Marín, R., 2018: «Una concepción recursiva del razonamiento probatorio», en Analisi e diritto, 2018, núm. 2.

IACOvello, F.M., I997: La motivazione della sentenza penale e il suo controllo in Cassazione, Milano: Giuffrè.

Igartua SalaVerRÍA, J., 2000: «Sobre el jurado y la motivación de su veredicto, una vez más», en Jueces para la Democracia, 38.

- 2003: La motivación de las sentencias, imperativo constitucional, Madrid: Centro de Estudios Políticos y Constitucionales.

LaUdan, L., 2003: «Is Reasonable Doubt Reasonable?», en Legal Theory, 9.

— «Por qué un estándar de prueba subjetivo y ambiguo no es un estándar», en Doxa, 28.

- 2006: Thuth, Error, and Criminal Law. An Essay in Legal Epistemology, Cambridge: Cambridge University Press; citado por la traducción castellana de VÁzQuez, C. y Aguilera, E.: Verdad, error y proceso penal. Un ensayo de epistemología jurídica, Madrid: Marcial Pons, 2013.

Nieto, A., 2000: El arbitrio judicial, Barcelona: Ariel.

Nino, C.S., 1993: «Derecho, moral, política», en Doxa, 14. 
Ovejero Puente, A.M., 2019: El derecho al juicio justo en el convenio europeo de derechos humanos, Valencia: Tirant lo Blanch.

Roberts, P., y Zuckerman A., 2004: Criminal Evidence, Oxford: Oxford University Press.

SAGÜÉs, N.P., 20I8: «La convencionalidad del veredicto inmotivado en el juicio por jurados», en $E l$ Derecho, Buenos Aires, lunes 22 de octubre de 2018, No 14.515, año LVI.

Schauer, F., 2009: Thinking Like a Lawyer, Cambridge (Mass.): Harvard University Press.

TARuffo, M., 1975: La motivazione della sentenza civile, Padova: Cedam. Citado por la traducción española de Córdova, L.: La motivación de la sentencia civil, Ciudad de México: Tribunal Electoral del Poder Judicial de la Federación, 2006.

- 1992: La prova dei fatti giuridici, Milano: Giuffrè; citado por la trad. española de Ferrer Beltrán, J.: La prueba de los hechos, Madrid: Trotta, 2002.

- 2010: «Consideraciones sobre prueba y motivación», en TARUfFo, M., ANdrÉz IbáŃEz, P. y CANDAU PÉrez, A: Consideraciones sobre la prueba judicial, Madrid: Fundación Coloquio Jurídico Europeo. 